\title{
KOMITMEN MANAJEMEN, PENGETAHUAN K-3 \& SIKAP K-3 DENGAN PENERAPAN SMK-3 PADA PEKERJA
}

\author{
Silvana Sidauruk, Adi Heru Sutomo, Hendarto Budiyono \\ Universitas Gadjah Mada, Fakultas Kedokteran, Bagian Ilmu Kesehatan Masyarakat, \\ adiheruhusodo@gmail.com
}

\begin{abstract}
The application of sophisticated technology, machines, installations, and hazardous materials are increasing in relation to industrialization. These could facili-tate the production activities, however they could also give potential danger. This research is intended to identify the correlation and influence between commitment of management, the knowledge of safety, and attitude toward safety in regards to the implementation of OHS management system among the workers of PT. X Batam Shipyard Company. This is an analytical correlative research with a cross-sectional design. The research subjects are 63 persons, consist of supervisors and employees who work at the production division of PT. X Batam. The type of analy-sis used Pearson Product Moment Correlation and multiple regression tests. The result shows that there is a positively significant correlation and influence between commitment of management, the knowledge of safety, and attitude toward safety in regards to the implementation of OHS management system $(R=0651 ; p=0.000)$, which has $42,4 \%$ contribution simultaneously. The result shows that commitment of management give the higher correlation and influence to the implementation of OHS management system $(\mathrm{r}=0,495 ; \mathrm{p}=0,000)$, which has $22,13 \%$ contribution, followed by attitude toward safety $(\mathrm{r}=0,372 ; \mathrm{p}=0,003)$ which has $12,17 \%$ contribution, and the knowledge of safety $(\mathrm{r}=0,321$; $\mathrm{p}=0,010)$ which has $8,1 \%$ contribution.
\end{abstract}

Key words: OHS management, commitment, knowledge, attitude

\begin{abstract}
Abstrak: Akhir-akhir ini penerapan teknologi canggih, misalkan mesin, peralatan moderen , dan bahan berbahaya semakin meningkat pemakaiannya untuk kebutuhan industrialisasi. Hal itu dapat memfasilitasi kegiatan produksi, tetapi juga bisa mem-berikan potensi bahaya. Penelitian ini bertujuan mengetahui hubungan dan pengaruh antara komitmen manajemen, pengetahuan tentang keselamatan, dan sikap terhadap keselamatan dalam hal pelaksanaan sistem manajemen K3antara para pekerja dari PT. X Batam Shipyard Company. Penelitian ini merupakan penelitian korelatif analitik dengan desain cross-sectional. Subjek penelitian adalah 63 orang, terdiri atas supervisor dan karyawan yang bekerja di divisi produksi. Jenis analisis yang digunakan Pearson Product Moment Korelasi dan beberapa uji regresi. Hasilnya menunjukkan bahwa terdapat korelasi positif yang signifikan dan pengaruh antara komitmen manajemen, pengetahuan tentang keselamatan, dan sikap terhadap kesela-matan dalam hal penerapan sistem manajemen K3 $(R=0.651, p=0,000)$, yang memiliki $42,4 \%$ kontribusi secara bersamaan. Hasilnya menunjukkan bahwa komit-men manajemen memberikan korelasi yang lebih tinggi dan berpengaruh pada pe-laksanaan sistem manajemen K3 ( $r=$ $0.495, \mathrm{p}=0,000$ ), yang memiliki kontribusi $22,13 \%$, diikuti oleh sikap terhadap keselamatan $(r=0.372, p=0,003)$ yang memiliki kontribusi $12,17 \%$, dan pengetahuan keselamatan $(r=$ $0.321, p=0,010$ ) yang memiliki kontribusi $8,1 \%$.
\end{abstract}

Kata Kunci: manajemen Keselamatan dan Kesehatan Kerja, pengetahuan, sikap

Penggunaan teknologi maju tidak dapat dielakkan, terutama pada era industrialisasi yang ditandai dengan proses mekanisasi, elektrikasi, modernisasi, dan globalisasi.
Penggunaan mesin-mesin, pesawat, instalasi dan bahan-bahan berbahaya terus meningkat sesuai kebutuhan industrialisasi, hal ini memberi kemudahan terhadap proses pro- 
duksi namun memberi dampak dan potensi bahaya dalam penggunaannya. Faktor lingkungan kerja yang tidak memenuhi syarat Keselamatan dan Kesehatan Kerja (K3), proses kerja tidak aman, serta sistem kerja yang semakin kompleks dan modern dapat menjadi ancaman tersendiri bagi K3. Kondisi lain adalah, masih kurangnya kesadaran dari sebagian besar masyarakat perusahaan, baik pengusaha maupun tenaga kerja akan pentingnya arti K3 (Tarwaka, 2008).

Berdasarkan data Jamsostek selama lima tahun terakhir, angka kecelakaan kerja setiap tahunnya semakin meningkat. Banyaknya kasus kecelakaan kerja ini bisa menjadi modal utama dalam upaya menjadikan manajemen K3 ini sebagai langkah awal. Sistem Manajemen Keselamatan dan Kesehatan Kerja (SMK3) merupakan bagian yang tidak terpisahkan dari sistem perlindungan tenaga kerja. Penerapan SMK3 di perusahaan akan menghindarkan diri dari risiko kerugian moral maupun material, kehilangan jam kerja, maupun keselamatan manusia dan lingkungan sekitarnya, yang diakibatkan oleh kecelakaan. Lebih jauh sistem ini dapat memberikan perlindungan bagi masyarakat sekitar perusahaan agar terhindar dari bahaya bahan-bahan proses industrialisasi, dan perlindungan masyarakat luas dari bahaya-bahaya yang mungkin ditimbulkan oleh produk-produk industri (Suardi, 2005).

Pencegahan kecelakaan atau program keselamatan dalam organisasi tidak akan berhasil tanpa dukungan dan peran serta manajemen puncak dalam organisasi. Manajemen harus memiliki komitmen nyata mengenai $\mathrm{K} 3$ sebagai bagian penting dalam keberhasilan usahanya, sehingga bukan sekadar untuk memenuhi formalitas Suardi, 2005). Penerapan manajemen K3 mendapatkan perhatian yang sangat serius di seluruh dunia dengan diterbitkannya standard OHSAS 18001 oleh berbagai perusahaan. Pemerintah Indonesia mengeluarkan Peraturan Pemerintah Nomor 50 Tahun 2012 tentang Penerapan SMK3, yang sebelumnya berupa Peraturan Menteri Tenaga Kerja (PerMenaKer) Nomor 05/men/1996 ten- tang SMK3.

Perusahaan galangan kapal merupakan salah satu perusahaan yang juga wajib menerapkan sistem ini di dalam kegiatan operasionalnya. Perusahaan galangan kapal dalam kegiatannya membuat dan memperbaiki kapal memiliki bermacam-macam jenis kegiatan dan potensi bahaya yang berpengaruh pada keselamatan dan kesehatan tenaga kerjanya. Kegiatan industri yang bergerak dalam bidang konstruksi secara umum mengandung potensi bahaya yang lebih tinggi dibanding industri lainnya akibat penggunaan alat-alat berat, peralatan, dan material berbahaya yang memiliki potensi kecelakaan yang tinggi (O. Abudayyeh, et al, 2005).

Berdasarkan pengamatan awal di PT X Batam, masih ditemukan beberapa komponen yang belum sesuai dengan elemen-elemen dari OHSAS 18001: 2007 yang diadopsi oleh perusahaan sebagai acuan system manajemen K3. Ketersediaan Alat Pelindung Diri (APD) masih terbatas, pakaian kerja yang kurang melindungi tenaga kerja dari bahaya pekerjaan, petugas kesehatan (paramedik) khusus belum terlatih, pemeriksaan medis secara berkala belum dilakukan, pelaksanaan sistem pencatatan dan pelaporan kecelakaan kerja, prosedur dan instruksi kerja, inspeksi serta pencatatan dan pelaporan K3 masih belum optimum.

Pengetahuan tenaga kerja PT. X mengenai K3 masih kurang, sebagian karyawan belum mengetahui resiko tidak menggunakan APD, pelatihan dan penyu-luhan K3 secara internal masih belum terlaksana secara rutin dan berkesinam-bungan, sosialisasi informasi mengenai $\mathrm{K} 3$ terkait bahaya di tempat kerja masih perlu ditingkatkan. Pengakuan dari beberapa tenaga kerja merasa belum pernah menda-patkan pelatihan K3, sebagian mengaku mendapatkan pelatihan dari tempat kerja sebelumnya. Kegiatan safety briefing atau toolbox meeting belum dilakukan, kegiatan safety meeting yang dijadualkan satu kali dalam seminggu belum dilakukan secara konsisten dan berkesinambungan. Beberapa tenaga kerja masih ada yang tidak menggunakan APD saat 
bekerja, tindakan mengambil jalan pintas, bahkan beberapa pekerja masih menganggap bahwa K3 meru-pakan tugas dan tanggung jawab petugas K3 saja.

Berdasarkan uraian di atas, penulis tertarik untuk meneliti hubungan serta pengaruh antara komitmen manajemen, pengetahuan dan sikap K3 tenaga kerja dengan penerapan SMK3 di PT. X Batam. Penelitian ini bertujuan mengevaluasi : (1) hubungan serta pengaruh antara komitmen manajemen, pengetahuan dan sikap K3 dengan penerapan SMK3, (2) hubungan serta pengaruh antara komitmen manajemen dengan penerapan SMK3, (3) hubungan serta pengaruh antara pengetahuan $\mathrm{K} 3$ dengan penerapan SMK3, 4) hubungan serta pengaruh antara sikap K3 dengan penerapan SMK3 di PT X kota Batam.

\section{BAHAN DAN CARA KERJA}

Jenis penelitian yang digunakan adalah analitik korelatif dengan rancangan potong lintang (cross sectional). Populasi penelitian terdiri atas semua supervisor dan tenaga kerja bagian produksi di PT. X Batam, yang berjumlah 173 orang. Besar sampel yang digunakam berjumlah 63 orang, yang diinklusi berdasarkan usia (18-55 tahun), tingkat pendidikan minimal setara SMU, dan masa kerja lebih dari enam bulan. Teknik pengambilan sampel menggunakan cara acak sederhana (simple random sampling).

Analisis yang digunakan adalah analiis univariat untuk melihat gambaran distribusi frekuensi setiap variabel, analisis bivariat (korelasi Pearson Product Moment) untuk melihat hubungan antara peubah bebas dan peubah terikat, dan analisis multivariat untuk melihat hubungan serta pengaruh antara peubah bebas terhadap peubah terikat dengan menggunakan uji regresi ganda.

\section{HASIL}

Berdasarkan analisis univariat diketahui bahwa dari 63 responden sebagian besar berada pada kategori usia 18-27 tahun (44,44\%), pendidikan terakhir setingkat SMU $(95,24 \%)$, belum pernah mendapatkan pendidikan/pelatihan K3 secara formal
$(98,41 \%)$, masa kerja 6 bulan -2 tahun $(85,7 \%)$ dan semua responden berjenis kelamin laki-laki. Sebagian besar responden memiliki pendidikan terakhir setara SMU dan mayoritas berasal dari pendidikan kejuruan dibanding pendidikan umum, karena dianggap sesuai dengan jenis pekerjaan. Sebagian besar responden memiliki masa kerja 6 bulan - 2 tahun. Hasil analisis deskriptif masing-masing variabel, sebagian besar responden menilai komitmen manajemen terkait K3 berada pada kategori rendah $(30,16 \%)$, pengetahuan K3 tenaga kerja berada pada kategori sedang $(31,75 \%)$, sikap K3 tenaga kerja berada pada kategori tinggi $(39,68 \%)$, penerapan SMK3 berada pada kategori rendah $(36,51 \%)$.

Berdasarkan hasil analisis korelasi pearson product moment pada Tabel 1, diketahui ada hubungan yang signifikan antara komitmen manajemen dengan penerapan SMK3. Artinya adanya peningkatan komitmen manajemen secara nyata akan meningkatkan penerapan SMK3. Ada hubungan yang signifikan antara pengetahuan K3 dengan penerapan SMK3, artinya adanya peningkatan pengetahuan $\mathrm{K} 3$ yang lebih baik secara nyata akan meningkatkan penerapan SMK3. Ada hubungan yang signifikan antara sikap K3 dengan penerapan SMK3, artinya peningkatan faktor sikap K3 yang lebih baik secara nyata akan mening-katkan penerapan SMK3.

Tabel 1. Hasil Uji Korelasi Pearson Product Moment

\begin{tabular}{|c|c|c|c|}
\hline \multirow{2}{*}{\multicolumn{2}{|c|}{ Variabel }} & \multicolumn{2}{|c|}{ Validitas } \\
\hline & & $\begin{array}{l}\text { Korelasi } \\
\quad \text { ( r) }\end{array}$ & $\begin{array}{l}\text { Sig } \\
(p)\end{array}$ \\
\hline \multirow{3}{*}{$\begin{array}{c}\text { Penerapan } \\
\text { SMK3 }\end{array}$} & $\begin{array}{l}\text { Komitmen } \\
\text { manajemen }\end{array}$ & 0,495 & 0,000 \\
\hline & Pengetahuan K3 & 0,321 & 0,010 \\
\hline & Sikap K3 & 0,372 & 0,003 \\
\hline
\end{tabular}

Berdasarkan hasil analisis multivariat pada tabel 2 dengan menggunakan uji regresi ganda pada Tabel 2, diperoleh nilai koefisien korelasi ganda yang disimbolkan dengan $R$ sebesar 0,651 ( $<<0,05)$. Artinya ada hubungan antara komitmen manajamen, pengeta- 
huan K3, dan sikap K3 secara bersama-sama dengan penerapan SMK3. Uji F menunjukkan ada pengaruh yang signifikan secara bersama-sama (simultan) dari variabel bebas komitmen manajemen, pengetahuan K3 dan sikap K3 terhadap penerapan SMK3, dengan nilai signifikansi $0,000(p<0,05)$.

Pengaruh variabel bebas secara parsial terhadap variabel terikat dapat dilihat dari taraf signifikansi uji t. Berdasarkan hasil uji analisis pada Tabel 2, nilai signifikansi untuk konstanta sebesar 0,382 ( $\mathrm{p}>0,5$ ), disimpulkan bahwa konstanta tidak signifikan terhadap model regresi. Sedangkan, nilai signifikansi variabel komitmen manajemen sebesar 0,000; pengetahuan K3 sebesar 0,014; dan sikap K3 sebesar 0,002 ( $<<0,05)$, sehingga dapat disimpulkan bahwa masing-masing variabel ini memiliki pengaruh yang signifikan terhadap penerapan SMK3.

Tabel 2. Hasil Uji Regresi

\begin{tabular}{|c|c|c|c|c|c|c|}
\hline $\begin{array}{c}\text { Varia- } \\
\text { bel }\end{array}$ & $\begin{array}{c}\text { Koefisien } \\
\text { regresi } \\
\text { (b) }\end{array}$ & SE & Beta & $\begin{array}{c}\text { T } \\
\text { hitung }\end{array}$ & Sig. & Ket \\
\hline $\begin{array}{l}\text { Kon- } \\
\text { stanta }\end{array}$ & $-8,949$ & 10,15 & & $-0,881$ & 0,382 & \\
\hline $\begin{array}{l}\text { Komit- } \\
\text { men } \\
\text { Mana- } \\
\text { jemen }\end{array}$ & 0,698 & 0,155 & 0,447 & 4,492 & 0,000 & sig \\
\hline $\begin{array}{l}\text { Pengeta- } \\
\text { huan K3 }\end{array}$ & 0,868 & 0,343 & 0,252 & 2,530 & 0,014 & sig \\
\hline Sikap K3 & 0,431 & 0,131 & 0,327 & 3,300 & 0,002 & sig \\
\hline \multicolumn{2}{|c|}{ R (Multiple R) } & \multicolumn{2}{|c|}{$=0,651$} & & & \\
\hline \multicolumn{2}{|l|}{ R Square } & \multicolumn{2}{|c|}{$=0,424$} & & & \\
\hline \multicolumn{2}{|c|}{ R Square (Adjusted) } & \multicolumn{2}{|c|}{$=0,395$} & & & \\
\hline \multicolumn{2}{|l|}{ F hitung } & \multicolumn{2}{|c|}{$=14,479$} & & & \\
\hline \multicolumn{2}{|l|}{ Sign. F } & \multicolumn{2}{|c|}{$=0,000$} & & & \\
\hline \multicolumn{2}{|c|}{ Ftabel $(5 \%, 2,59)$} & \multicolumn{2}{|c|}{$=3,15$} & & & \\
\hline \multicolumn{2}{|c|}{ ttabel $(5 \%, 59)$} & \multicolumn{2}{|l|}{$=2$} & & & \\
\hline \multicolumn{2}{|l|}{$\alpha$} & \multicolumn{2}{|c|}{$=0,05$} & & & \\
\hline
\end{tabular}

Persamaan regresi berdasarkan nilai koefisien regresi pada Tabel 2 digambarkan sebagai berikut:

$$
\begin{aligned}
& Y=-8,949+0,698 X 1+0,868 X 2+ \\
& 0,431 X 3
\end{aligned}
$$

1) Konstanta (b0) $=-8,949$

Nilai signifikansi konstanta sebesar 0,382 ( $>0,05$ ), artinya nilai konstanta tidak signifikan untuk memprediksi nilai pene- rapan SMK3.

2) Koefisien $X 1=0,698$

Nilai ini menunjukkan bahwa semakin baik komitmen manajemen, maka penerapan SMK3 akan meningkat sebesar 0,698 satuan. Adanya peningkatan komitmen manajamen yang semakin baik dapat mempengaruhi peningkatan penerapan SMK3.

3) Koefisien $X 2=0,868$

Nilai ini menunjukkan semakin baik pengetahuan K3, maka penerapan SMK3 akan meningkat sebesar 0,868 satuan. Artinya peningkatan pengetahuan K3 yang semakin baik mempengaruhi terjadinya peningkatan penerapan SMK3, dengan asumsi variabel lain tetap.

4) Koefisien $X 3=0,431$

Nilai ini menunjukkan semakin baik sikap K3, maka penerapan SMK3 akan meningkat sebesar 0,431 satuan. Artinya peningkatan sikap K3 yang semakin baik mempengaruhi terjadinya peningkatan penerapan SMK3, dengan asumsi variabel yang lain tetap.

Berdasarkan hasil rangkuman uji hipotesis pada Tabel 3, diperoleh bahwa peubah yang memiliki hubungan serta pengaruh paling besar terhadap penerapan SMK3 adalah variabel komitmen manajemen, dengan memberikan sumbangan efektif sebesar $22,13 \%$, diikuti peubah sikap sebesar $12,17 \%$, dan pengetahuan K3 sebesar $8,1 \%$. Sehingga diperoleh sumbangan efektif total variabel bebas sebesar $42,40 \%$, sedangkan $57,60 \%$ sisanya dipengaruhi oleh faktor lain. Hasil analisis deskriptif menunjukkan bahwa penerapan SMK3 di PT. X masih rendah. Hal ini terlihat dari belum optimalnya; pengendalian sumber bahaya di tempat kerja, penyediaan APD baik dalam jumlah maupun kualitas, penyediaan sumber daya yang diperlukan untuk pelatihan K3, sosialisasi SOP maupun instruksi kerja, dan belum ada pemeriksaan kesehatan secara berkala. Penerapan MK3 di tempat kerja bertujuan untuk meningkatkan kinerja $\mathrm{K} 3$, mencegah dan mengurangi terjadinya kecelakaan dan PAK. Penerapan MK3 membutuhkan dukungan dari seluruh tingkatan manajemen 
dan juga keterlibatan tenaga kerja.

Tabel 3. Rangkuman Pengujian Hipotesis

\begin{tabular}{lcccc}
\hline $\begin{array}{c}\text { Hubungan } \\
\text { Antar } \\
\text { Variabel }\end{array}$ & $\begin{array}{c}\text { Koefi- } \\
\text { sien } \\
\text { Kore- } \\
\text { lasi }\end{array}$ & $\begin{array}{c}\text { Sig } \\
\text { (p) }\end{array}$ & $\begin{array}{c}\text { Sumbang } \\
\text { an } \\
\text { Efektif }\end{array}$ & $\begin{array}{c}\text { Varia- } \\
\text { bel lain }\end{array}$ \\
\hline $\begin{array}{l}\text { Komitmen } \\
\text { Manajemen } \\
\text { dengan }\end{array}$ & 0,495 & 0,000 & $22,13 \%$ & $77,87 \%$ \\
Penerapan & & & & \\
$\begin{array}{l}\text { Pengetahuan } \\
\text { K3 dengan }\end{array}$ & 0,321 & 0,010 & $8,10 \%$ & $91,90 \%$ \\
Penerapan & & & & \\
SMK3 & & & & \\
Sikap K3 & 0,372 & 0,003 & $12,17 \%$ & $87,30 \%$ \\
dengan & & & & \\
$\begin{array}{l}\text { Penerapan } \\
\text { SMK3 }\end{array}$ & & & & \\
Komitmen & 0,651 & 0,000 & $42,40 \%$ & $57,60 \%$ \\
Manajemen, & & & & \\
Pengetahuan & & & & \\
K3, dan & & & & \\
Sikap K3 & & & & \\
dengan & & & & \\
Penerapan & & & & \\
\hline
\end{tabular}

\section{PEMBAHASAN}

\section{Komitmen Manajemen}

Hasil penelitian secara deskriptif menunjukkan bahwa komitmen manajemen terkait K3 berada pada kategori rendah. Berdasarkan hasil analisis diketahui bahwa, ada hubungan antara komitmen manajemen dengan penerapan SMK3 pada tenaga kerja di PT. X, artinya jika komitmen manajemen baik maka penerapan SMK3 akan meningkat. komitmen manajemen terhadap K3 merupakan salah satu yang mempengaruhi performa K3 para tenaga kerja, karena komitmen manajemen terhadap K3 merupakan dasar yang sangat penting dari program K3. Hal ini dapat terlihat dari belum optimalnya keterlibatan manajemen puncak dalam pengawasan langsung kondisi $\mathrm{K} 3$ di tempat kerja, pertimbangan isu-isu K3 dalam kegiatan produksi, penyediaan sumber daya dan fasilitas K3, seperti APD dan program pelatihan K3 di tempat kerja. Keberhasilan dari MK3 tergantung komitmen seluruh tingkatan dan fungsi dalam organisasi, dan seba- gian besarnya oleh manajemen puncak ( $\mathrm{T}$. Rundmo, et al, 2002 dan Fernandez-Muňiz, et al, 2011).

Penerapan MK3 membutuhkan dukungan dari seluruh tingkatan manajemen dan juga keterlibatan tenaga kerja. Komitmen terhadap keselamatan dapat didefinisikan sebagai identifikasi individu dan keterlibatan dalam aktifitas keselamatan dengan ciri-ciri memiliki penerimaan yang kuat dan kepercayaan terhadap tujuan keselamatan perusahaan dan kemauan untuk mengerahkan usaha meningkatkan keselamatan di tempat kerja. Komitmen berkaitan dengan kesadaran dan kewajiban (normative commitment) sebagai bentuk keterlibatan dan loyalitas pihak manajemen, yang harus dipenuhi terkait kondisi K3 di tempat kerja (Meyer, et al, 1997 dan Steers, 1997).

\section{Pengetahuan K3}

Berdasarkan hasil penelitian secara deskriptif, pengetahuan $\mathrm{K} 3$ para tenaga kerja berada pada kategori sedang. Meskipun program pendidikan/pelatihan $\mathrm{K} 3$ belum optimal, namun hasil penelitian menunjukkan bahwa sebagian besar tenaga kerja sudah memiliki pengetahuan mengenai K3. Hal ini disebabkan adanya upaya dari pihak petugas $\mathrm{K} 3$ yang memberikan pengetahuan K3 melalui safety meeting, teguran dan nasehat melalui kegiatan inspeksi K3, dan beberapa poster K3 yang dipasang meskipun masih belum optimal. Walaupun secara formal belum ada pelatihan tentang $\mathrm{K} 3$, tenaga kerja bisa juga memperoleh informasi secara informal melaui media massa baik cetak, audio maupun audiovisual, serta melalui pengalaman hidup lainnya (Notoatmodjo, 2005).

Berdasarkan hasil analisis, diketahui bahwa ada hubungan antara pengetahuan K3 dengan penerapan SMK3 pada tenaga kerja di PT X, artinya jika pengetahuan K3 baik maka penerapan SMK3 akan meningkat. Pengetahuan juga merupakan domain yang sangat penting untuk terbentuknya tindakan seseorang.

Perilaku yang didasari oleh pengetahuan, kesadaran dan sikap yang positif akan 
bersifat langgeng. Pengetahuan tidak hanya diperoleh melalui pendidikan formal, namun juga melalui pendidikan nonformal seperti percakapan, media massa baik cetak, audio maupun audiovisual, serta melalui pengalaman hidup lainnya (Notoatmodjo, 2005). Namun demi tercapainya penerapan K3 yang lebih baik perlu adanya pengetahuan K3 yang seragam antar setiap tenaga kerja7, untuk itu perlu adanya pendidikan/pelatihan $\mathrm{K} 3$ yang terprogram dan dilaksanakan secara berkesinambungan.

\section{Sikap K3}

Berdasarkan hasil analisis deskriptif, sikap K3 para tenaga kerja berada pada kategori tinggi. Meskipun pada hasil pengamatan di lokasi kerja banyak ditemukan perilaku tidak aman, namun hasil penelitian menunjukkan bahwa tenaga kerja memiliki sikap K3 yang baik. Secara naluriah manusia menghindari kecelakaan, keinginan ini tidak terbatas pada orang-orang yang memang telah mempersiapkan diri agar kecelakaan tidak terjadi, melainkan juga untuk semua orang, bahkan orang yang perilakunya membahayakan sekalipun tidak menginginkan kecelakaan menimpa dirinya (Winarsunu, 2008).

Berdasarkan hasil analisis, diketahui bahwa ada hubungan antara sikap K3 dengan penerapan SMK3 pada tenaga kerja di PT. $\mathrm{X}$, artinya jika sikap K3 baik maka penerapan SMK3 akan meningkat. Sikap mempengaruhi perilaku lewat suatu proses pengambilan keputusan yang teliti dan beralasan. Seseorang akan melakukan suatu perbuatan apabila ia memandang perbuatan tersebut positif dan percaya bahwa orang lain ingin agar ia melakukannya. Selanjutnya Azjen (1988) mengatakan, keyakinan mengenai tersedia atau tidaknya kesempatan dan sumber yang diperlukan yang nantinya menentukan intensi dan perilaku tertentu.

Respon konatif pada dasarnya merupakan kecenderungan untuk berbuat. Dalam bentuk verbal, intensi ini terungkap lewat pernyataan dan keinginan untuk melakukan. Dengan mengetahui sikap seseorang tidaklah berarti kita dapat memprediksikan perila- kunya dengan akurasi yang tinggi, namun sikap tetap mendasari bentuk-bentuk perilaku yang secara konsisten diperlihatkan seseorang terhadap objek-objek sosial dalam jangka waktu tertentu (Robbins, et al, 2009). Pembentukan sikap juga dipengaruhi oleh pengalaman pribadi, kebudayaan, media massa, institusi atau lembaga tertentu, dan faktor emosi dalam diri individu yang bersangkutan.

\section{Hubungan Komitmen Manajemen, Pengeta- huan K3, dan Sikap K3 dengan Penerapan SMK3 pada Tenaga Kerja}

Berdasarkan hasil analisis diketahui bahwa, ada hubungan komitmen manajemen, pengetahuan $\mathrm{K} 3$, dan sikap $\mathrm{K} 3$ dengan penerapan SMK3 pada tenaga kerja di PT. $\mathrm{X}$, artinya jika komitmen manajemen, pengetahuan K3, dan sikap K3 baik, maka penerapan SMK3 akan meningkat. Keterlibatan seluruh pihak manajemen dan staf dalam program K3, sebagai bagian dari seluruh pihak manajemen $\mathrm{K} 3$, memberikan peningkatan efektivitas yang signifikan bagi program K3 tersebut.

Pendidikan dan pelatihan memberikan kontribusi yang penting bagi penerapan manajemen kualitas yang fokus pada K3 (safety-focussed Quality Management). Hal ini menunjukkan eratnya kaitan pengetahuan K3 yang dihasilkan dari pendidikan dan pelatihan tersebut dengan penerapan MK3. Begitu pula hasil penelitian Rooke dan Clark (2005) yang menyebutkan bahwa inisiatif K3 yang berlandaskan pengetahuan dapat menciptakan penerapan MK3 yang baik pada suatu manajemen perusahaan. Namun, kurangnya pemahaman tentang manfaat penerapan SMK3 mengakibatkan tingkat aplikasi atau penerapannya tetap rendah. Merujuk pada teori Bloom, pengetahuan responden belum sampai pada tingkat aplikasi, yakni tingkatan yang menunjukkan kemampuan untuk menggunakan atau mengaplikasikan prinsip yang diketahui pada situasi yang lain. Tingkatan pengetahuan responden berada pada tahap sekedar 'tahu' dan memahami.

Hasil analisis deskriptif menunjukkan variabel sikap K3 dalam kategori tinggi de- 
ngan penerapan SMK3 dalam kategori rendah. Hasil penelitian ini membuktikan bahwa sikap K3 tenaga kerja saja tidak cukup untuk menunjukkan keberhasilan penerapan manajemen K3 suatu perusahaan, karena sikap K3 yang positif belum tentu disertai dengan tindakan yang sejalan dalam membentuk suatu sistem yang baik dalam penerapan manajemen $\mathrm{K} 3$, atau sebaliknya. Sikap K3 para tenaga kerja dapat lebih ditingkatkan jika perusahaan dan para manajer juga menunjukkan komitmen dalam penerapan K3. Peningkatan persepsi tenaga kerja terhadap kepedulian manajemen akan kesejahteraan mereka melalui K3 memberikan hasil yang positif lebih dari sekedar perbaikan perilaku K3.

\section{KESIMPULAN}

Berdasarkan hasil penelitian, pengujian hipotesis dan pembahasan, dapat disimpulkan bahwa ada hubungan positif serta pengaruh yang signifikan antara komitmen manajemen, pengetahuan $\mathrm{K} 3$, dan sikap K3 dengan penerapan SMK3 pada tenaga kerja di PT. X kota Batam, ada hubungan positif serta pengaruh yang signifikan antara komitmen K3 dengan penerapan SMK3 pada tenaga kerja di PT. X kota Batam, ada hubungan posittif serta pengaruh yang signifikan antara pengetahuan K3 dengan penerapan SMK3 pada tenaga kerja di PT. X

\section{DAFTAR PUSTAKA}

Abudayyeh, O., Fredericks, T. K., Butt, S. E., \& Shaar, A. 2005. An investigation of management's commitment to construction safety. International Journal of Management, 24 (2006), 167-174.

Fernandez-Muňiz, B., Montes-Peỏn, J. M., \& Vazques-Ordás, C. J. 2011a.

Ismail, Z., Doostdar, S. \& Harun, Z. 2011. Factors influencing the implementation of safety management system for construction sites. Safety Science, 50 (2012) 418-423.

Meyer, J. P. \& Allen, N. J. 1997. Commitment in the Workplace: Theory, Research and Application. Thousand Oaks, CA: Sage Publication.

Notoatmodjo, S. 2005. Promosi Kesehatan: Teori dan Aplikasi. Jakarta: PT Rineka Cipta.

Robbins, S. P. \& Judge, T. A. 2009. Organizational Behaviour. 13th Edition. New Jersey: Pearson kota Batam dan ada hubungan positif serta pengaruh yang signifikan antara sikap K3 dengan penerapan SMK3 pada tenaga kerja di PT. X kota Batam.

Saran untuk pihak manajemen PT. X Kota Batam hendaknya dapat meningkatkan komitmennya terhadap penerapan SMK3, terutama dalam hal pengawasan langsung terhadap pelaksanaan $\mathrm{K} 3$, memberikan pelatihan K3 yang berkesinambungan di internal perusahaan, mengadakan safety talk atau toolbox meeting harian, mengikutsertakan petugas $\mathrm{K} 3$ dalam pelatihan yang bersertifikasi di luar perusahaan, mengadakan refreshment secara berkala, agar setiap tenaga kerja lama maupun tenaga kerja baru memiliki tingkat pengetahuan K3 yang merata, sehingga diharapkan dapat meningkatkan sikap dan perilaku tenaga kerja yang aman dalam bekerja.

Tenaga kerja hendaknya melakukan tindakan yang aman saat bekerja, yakni dengan menggunakan APD, mematuhi SOP pekerjaan, serta proaktif dalam melaporkan temuan-temuan dan kondisi K3 yang tidak aman di tempat kerja. Perlu dilakukan penelitian lebih lanjut terhadap faktor-faktor lain yang dinilai berpengaruh terhadap penerapan SMK3 di perusahaan, sehingga dapat digunakan sebagai bahan masukan untuk pengembangan konsep-konsep penerapan SMK3 di tempat kerja.

Education, Inc.

Rundmo, T. \& Hale, A. R. 2002. Manager's attitudes towards safety and accident prevention. Safety Science, 41 pp. 557-574.

Safety climate in OHSAS 18001-certified organizations: Antecedents and consequences of safety behavior. Accident Analysis and Prevention, 45 (2012) 745-758.

Setyawati, L. 2000. Pengaruh Peralatan yang Tidak Ergonomis Terhadap Kelelahan Kerja dan Stres Psikososial. Proceeding Seminar Nasional Ergonomi. Guna Widya, Surabaya.

Steers, R. M. 1997. Efektivitas Organisasi. Terjemahan oleh Magdalena Jamin. Jakarta: Erlangga.

Steers, R. M., \& Porter, L. W. 1983. Motivation and work behavior. New York: McGraw-Hill.

Suardi, R. 2005. Sistem Manajemen Keselamatan 
184 Jurnal Media Kesehatan, Volume 8 Nomor 2, Agustus 2014, hlm 100-204

dan Kesehatan Kerja.Jakarta: Pusat Pengembangan Masyarakat (PPM).

Tarwaka. 2008. Kesehatan dan Keselamatan Kerja: Manajemen dan Implementasi K3 di
Tempat Kerja. Surakarta: Harapan Press.

Winarsunu, T. 2008. Psikologi Keselamatan Kerja. Malang: UMM Press. 